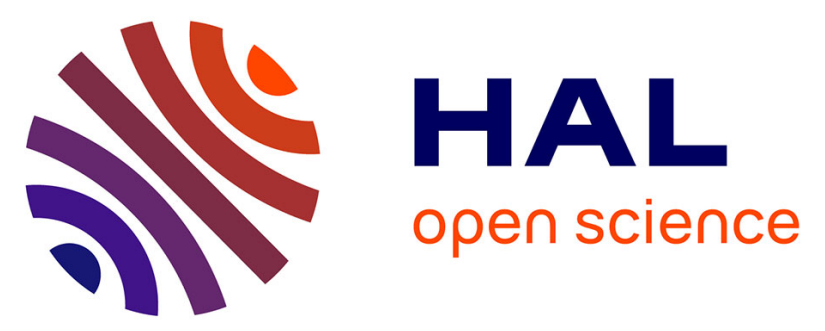

\title{
Management of postoperative bladder emptying after proctectomy in men for rectal cancer. A retrospective study of 190 consecutive patients
}

Cécile Bouchet-Doumenq, Jérémie H. Lefevre, Malika Bennis, Najim Chafai, Emmanuel Tiret, Yann Parc

\section{To cite this version:}

Cécile Bouchet-Doumenq, Jérémie H. Lefevre, Malika Bennis, Najim Chafai, Emmanuel Tiret, et al. Management of postoperative bladder emptying after proctectomy in men for rectal cancer. A retrospective study of 190 consecutive patients. International Journal of Colorectal Disease, 2016, 31 (3), pp.511-518. 10.1007/s00384-015-2471-8 . hal-01305528

\section{HAL Id: hal-01305528 \\ https://hal.sorbonne-universite.fr/hal-01305528}

Submitted on 21 Apr 2016

HAL is a multi-disciplinary open access archive for the deposit and dissemination of scientific research documents, whether they are published or not. The documents may come from teaching and research institutions in France or abroad, or from public or private research centers.
L'archive ouverte pluridisciplinaire HAL, est destinée au dépôt et à la diffusion de documents scientifiques de niveau recherche, publiés ou non, émanant des établissements d'enseignement et de recherche français ou étrangers, des laboratoires publics ou privés. 
Management of postoperative bladder emptying after proctectomy in men for rectal cancer. A retrospective study of 200 consecutives patients.

Cécile BOUCHET-DOUMENQ, M.D. ${ }^{1}$, Jeremie H. LEFEVRE, M.D., PhD ${ }^{1}$, Malika BENNIS, M.D. ${ }^{1}$, Najim CHAFAI, M.D. ${ }^{1}$, Emmanuel TIRET, M.D. ${ }^{1}$, Yann PARC, M.D., Ph.D. ${ }^{1}$

${ }^{1}$ Department of Digestive Surgery, Hôpital Saint-Antoine, Assistance Publique Hôpitaux de Paris

Université Pierre et Marie Curie, Paris VI, 184 rue du Faubourg Saint-Antoine, 75012, Paris, France

Corresponding Author:

Pr Jeremie Lefevre, Department of Digestive Surgery, Hôpital Saint-Antoine, Assistance Publique Hôpitaux de Paris, Université Pierre et Marie Curie, Paris VI, 184 rue du Faubourg Saint-Antoine, 75012, Paris, France

Tel : 00331492825 47, Fax : 0033149282548

e-mail: jeremie.lefevre@sat.aphp.fr

Key words: rectal cancer; colorectal anastomosis; urinary dysfunction; suprapubic catheterization ; transurethral catheterization. 


\section{ABSTRACT}

Purpose: Evaluation of urinary drainage after rectal resection and identification of criteria associated with postoperative urinary dysfunction (UD). UD remains a clinical problem for up to two thirds of patients after rectal resection. Currently there are no guidelines concerning duration or type of drainage.

Methods: 200 consecutive rectal resections (abdomino-perineal resection (APR=50), mechanical coloanal anastomosis $(\mathrm{MechCAA}=50)$, manual coloanal anastomosis $(\mathrm{ManCAA}=50)$, colorectal anastomosis $(\mathrm{CRA}=50)$ ) in male patients were included. In patients with transurethral catheterization (TUC), the drainage was removed at day 5. Patients with suprapubic catheterization (SPC) underwent drainage removal according to the results of a clamping test at day 5. UD was defined as drainage removal after day 6 and/or acute urinary retention (AUR).

Results: Drainage types were: SPC $(n=142,71 \%)$ and TUC $(n=58,29 \%)$. SPC was used more frequently after total mesorectal excision (TME) (APR, ManCAA, MechCAA) (82\%-90\%). Complications rates of SPC and TUC were $15 \%$ and $6 \%$. The clamping test was positive for 69 patients (51\%) and SPC was removed before/on POD6 without any episodes of AUR. After TUC removal, 2 patients (4\%) had AUR. 72(38\%) patients had UD: $11(6 \%)$ were discharged with an indwelling catheter and in 61(32\%) the catheter was removed after day 6. Three independent factors were associated with UD: diabetes ( $\mathrm{OR}=2.9 ;(1.2-7.7))$, urological history $(\mathrm{OR}=2.9 ;(1.2-7.6))$ and TME $(\mathrm{OR}=5.2 ;(2.3-13.7))$.

Conclusion: The UD rate after surgery for rectal cancer was 38\%. Drainage by SPC is not associated with any major morbidity. The clamping test is accurate to prevent AUR. The three risk factors may serve to select good candidates for early catheter removal. 


\section{INTRODUCTION}

Modern rectal cancer treatment is based on radical surgery with nerve preservation and total mesorectal excision [9, 21]. Mesorectal excision improves oncological outcome but it may result in decreased sexual [14], urogenital and anorectal function [7, 8, 18], unless careful attention is given to nerve preservation.

Urinary dysfunction remains a clinical problem for up to two thirds of patients after rectal resection, especially for those with low rectal cancer [3]. The percentage of urinary dysfunction after rectal cancer surgery varies in the literature and depends on surgical expertise and patients' characteristics. There are several possible reasons for urinary dysfunction. Intraoperative nerve damage seems to be the main cause. Impaired preoperative urinary function may also contribute to the development of postoperative dysfunction $[3,4,8]$. Overall, several risk factors have been suggested: male gender, advanced age, tumour location, rectal cancer rather than colon cancer, longer operative time, additional pelvic procedure, surgical drain, neoadjuvant chemoradiotherapy and pelvic infection [5].

Although voiding difficulties are transitory in most patients, temporary bladder drainage is justified [6]. In the literature the optimal duration of postoperative urinary drainage is unclear [22]. The authors keep urinary catheters in situ between one and five days. Lee and $a l$. showed that urinary catheter removal before the fifth postoperative day was an independent risk factor for acute urinary retention after rectal cancer surgery [12]. The type of drainage is not clear either. Suprapubic catheterization seems to give rise to fewer bladder and urethral symptoms but, to our knowledge, has not yet been proven to be superior to transurethral catheterization $[3,10$, 17]. Current French Guidelines recommend suprapubic catheterization (SPC) if the anticipated duration of drainage exceeds four days [1] but do not specify a standard delay of bladder drainage after colorectal surgery.

In our department of digestive surgery, SPC is used in the majority of male patients undergoing rectal cancer surgery. Some studies suggest that the rates of urinary tract infection [19, 20], second catheterization and urinary symptoms (pain, bladder irritation) are lower with SPC than with transurethral catheterization (TUC) $[15,17]$. The benefits of SPC include both easier management and better tolerance. Moreover, it allows for testing bladder voiding without drainage removal. On the other hand, it is a more invasive system.

The aim of this study was to evaluate our practice of urinary drainage after rectal resection and to identify factors predictive of postoperative urinary dysfunction. 


\section{METHODS}

\section{Patients}

We included retrospectively 200 male patients from our department undergoing rectal resection. The sample consisted of 50 patients with abdomino-perineal resection (APR), 50 patients with mechanic coloanal anastomosis (MechCAA), 50 patients with manual coloanal anastomosis (ManCAA) and 50 patients with colorectal anastomosis (CRA). Inclusions were performed using a retrospective database of all rectal cancer patients operated in our department. Inclusions were performed back to front (??) starting on 1/12/2012 until 50 patients were included in each group. This method allowed us to have a sample of successive, recent cases and the same number of patients in each group.

\section{Database}

The following baseline characteristics were documented: comorbidity, ASA (American Society of Anaesthesiologists) score, tumour characteristics (including origin (?) and location), operative details, histopathological examination of the resected specimen, postoperative analgesia, early and late complications. All data were added to an anonymous database. In addition, we recorded type and duration of bladder drainage as well as any associated complications and their management.

\section{Surgical Technique}

The standard surgical technique for all patients included full mobilization of the splenic flexure, high ligation of the inferior mesenteric artery and vein, and total or partial mesorectum excision [16]. The choice of intervention was defined by tumor localization, previous surgery and past medical history. The type of reconstruction and anastomotic technique were left to the surgeons' discretion. A straight coloanal anastomosis was avoided whenever possible. The pelvis was routinely drained with a suction drain in the presacral space, which was removed 48 hours after surgery[2]. Rectal resections with a coloanal anastomosis were routinely covered with a temporary loop ileostomy. Rectal resections with a colorectal anastomosis were protected if the anastomosis was low. An omentoplasty was realized in all abdominoperineal resections without shred (??).

\section{Postoperative Urinary Management}

If a suprapubic catheter (SPC) was used, it was inserted at the end of the procedure. It was clamped on the fifth postoperative day and removed if the urinary residual was less than 50cc. If the urinary residual was not satisfactory, the patient received an alpha-blocker (Alfuzonide LP 10) and the clamping test was repeated until 
the urinary residual was acceptable. Patients with a persistently negative test were discharged with the SPC and referred to an urologist.

If the choice was transurethral catheterization (TUC), the catheter was taken out once morphine analgesia had been discontinued. It was removed on day 5 in patients without complications or bladder resection.

\section{Analgesic protocol}

Analgesic protocols were morphine patient controlled analgesia (PCA) with or without a wound catheter delivering local analgesia or epidural morphine pump alone. Pumps were routinely removed on the third postoperative day prior to clamping of the urinary catheter.

\section{Evaluation of Urinary Function}

We recorded preoperative dysfunction, type of catheter, interval between the first clamping of SPC and its removal, complications after catheter removal and their management. Urinary dysfunction was defined as catheter removal after the sixth postoperative day and/or any episode of acute urinary retention.

\section{Statistical analysis}

Descriptive analyses are presented as median (range) or mean $+/$ - standard deviation for quantitative data and as number of patients (percentage of patients) for categorical data. The correlation between the urinary dysfunction and the variables of interest was studied by univariate analysis (Chi-square). All tests were two-sided, and a pvalue $<0.05$ was considered to be significant. The multivariate analysis was performed using a backward stepwise logistic regression model that included all variables with a p-value $<0.2$ in univariate analysis. Results of this multivariate analysis are shown as odds ratio (OR); [95 percent confidence interval]. All analyses were performed using JMP9 (SAS Institute Inc, Cary, NC, USA).

\section{RESULTS}

\section{Patients}

In order to obtain 50 men in each group, patients operated between December 2012 and January 2006 were included. Median age was 63 years (19-92) and 173 patients $(86.5 \%)$ had an ASA score of 1 or 2. Patients' characteristics did not differ between the four groups (Table 1). 
Due to the location of the tumor, the rate of neoadjuvant radiotherapy was significantly different in the 4 groups: APR (84\%), MechCAA (76\%), ManCAA (70\%), CRA (18\%), p<0.001.

\section{Intervention}

A laparoscopic approach was performed in 84 patients (42\%). The rate of laparoscopy ranged from $68 \%$ for CRA to $22 \%$ for APR $(\mathrm{P}<0.0001)$. However, the conversion rate was not significantly different between the four groups. The bladder was drained with a suprapubic catheter (SPC) in 142 patients (71\%) and a transurethral catheter (TUC) in 58 patients (29\%). A significant difference in the rate of SPC use was observed between patients who underwent total mesorectal excision (TME) (APR, ManCAA or MechCAA) (82\%-90\%) versus partial mesorectal excision (PME) with CRA $(28 \%), \mathrm{p}<0.001$.

\section{Urinary Management}

\section{Associated urological procedures}

During surgery, there were 3 bladder resections, 4 prostatic resections, $2 \mathrm{JJ}$ stents (for bladder and ureteric lesions) and 1 ureteric resection. All patients with bladder lesions were drained with TUC for 10 to 17 days. All patients with prostatic lesions were drained with SPC for 7 to 57 days. As urinary drainage was longer in patients with associated urological procedures, we excluded these patients from the study $(n=190)$.

\section{Suprapubic catheterization without associated urological surgery $(\mathrm{n}=136)$}

SPC was used in the majority of patients undergoing TME (90\%). The complication rate of SPC was $15 \%$ and mainly due to leakage $(4.3 \%)$ or accidental catheter removal (4.3\%), (table 2). The clamping test was positive for 69 patients $(51 \%)$ and their SPC were removed before or on POD6. There were no episodes of acute urinary retention in this group, giving the clamping test a positive predictive value of $100 \%$. The rate of removal before POD6 ranged from $44 \%$ after MechCAA to $62 \%$ after ManCAA (table 2).

For the remaining patients with a negative test, removal of SPC was possible at POD10 or at POD21 for $82.7 \%$ and $93.5 \%$ of patients, respectively. The SPC could not be taken out in 9 patients $(6.5 \%)$ and they left the hospital with the catheter in situ.

Urinary catheter without associated urological surgery $(n=54)$

Transurethral catheterization was mainly used after PME and CRA (67\%), table 2. Its complication rate was $6 \%$ (infection: $\mathrm{n}=8,5.8 \%$ ). The TUC was removed in all patients before POD6. After TUC removal, 2 patients (4\%) developed AUR and were discharged with an indwelling TUC. (Table 2) 


\section{Urinary dysfunction}

Overall, 72 patients $(38 \%)$ had urinary dysfunction: $11(6 \%)$ were discharged with an indwelling urinary catheter and in $61(32 \%)$ patients the bladder catheter was removed after POD6.

\section{Ablation Failures}

Details of patients with failed catheter removal are given in table 3. All patients except one, had at least one of the three classical predisposing factors (diabetes mellitus, previous urological history or neoadjuvant radiotherapy). They were all treated with alpha-blockers and recovered a normal urinary function after a median period of drainage ranging from 22 to 259 days. The patient with the longest drainage period (259 day) had a local recurrence needing a prolonged drainage, (table 3).

\section{Risk factors of urinary dysfunction}

The rates of urinary dysfunction were $51 \%$ for APR, 50\% for MechCAA, $36.2 \%$ for ManCAA and $14.3 \%$ for CRA. There was no significant difference between APR, MechCAA and ManCAA ( $\mathrm{p}=0.269)$ but urinary dysfunction was significantly less frequent after PME and CRA $(\mathrm{p}<0.0001)$.

In univariate analysis, five risk factors were significantly associated with urinary dysfunction: diabetes mellitus $(\mathrm{p}=0.036)$, previous urological history $(\mathrm{p}=0.003)$, neoadjuvant radiotherapy $(\mathrm{p}=0.016)$, laparoscopic surgical procedure $(\mathrm{p}=0.002)$ and total mesorectal excision $(\mathrm{p}<0.0001)$, table 4 .

In multivariate analysis, only three risk factors were independent: diabetes mellitus $(\mathrm{OR}=2.9(1.2-7.7))$, previous urological history $(\mathrm{OR}=2.9(1.2-7.6))$ and total mesorectal excision $(\mathrm{OR}=5.2(2.3-13.7))$, table 4 .

We evaluated the dysfunction urinary rate according to the number of independent risk factors. Out of 35 patients without any risk factors, only four patients (11\%) developed urinary dysfunction. Among patients with one, two or three risk factors, the rates of urinary dysfunction were: $36 \%(40 / 110), 61 \%(25 / 40)$ and $75 \%(3 / 4)$, respectively.

\section{DISCUSSION}

We studied retrospectively the urinary function in 200 men after proctectomy for rectal cancer. In the majority of patients $(71 \%)$ the bladder was drained with a SPC. We observed few complications (15\%) and the clamping test had an accuracy of $100 \%$. The urinary function was a clinical problem for 72 men (38\%) including 11 patients (5.8\%) who were discharged with an indwelling urinary catheter. During follow-up all SPC could eventually be removed. We found three independent risk factors: diabetes, urologic history and TME. 
One of the major interests of this study is its homogeneous population consisting exclusively of male patients undergoing surgery for rectal cancer. To our knowledge, all previous publications included either colorectal resections and/or women or evaluated fewer patients. Moreover, we studied four different procedures for rectal cancer resection according to the tumour location, which allows a precise comparison.

SPC were used in the majority of patients (71.6\%), as this is the policy of our unit. The lower the anastomosis was, the more frequently a SPC was used. The complication rate associated with SPC was $15 \%$ and all complications were minor. Infection rates were similar for SPC and TUC. However, there was no episode of acute urinary retention (AUR) after SPC removal unlike TUC removal (4\% of AUR). This rate is much lower than the one reported by Benoist et al. in their randomized study comparing one day versus five days of urinary drainage after proctectomy [3]. They observed a 31\% rate of voiding problems in the 1-day group and $10 \%$ in the 5-days group even though half of the included patients were women. We believe that this difference may be explained by both the wide use of SPC and the routine clamping test in our unit. Indeed, in their comparative study, the rate of acute retention was $72 \%$ for patients operated for a low rectal cancer with 1-day urinary drainage. This observation confirms the interest of a more prolonged drainage with SPC.

Gerstenberg et al. studied bladder function by urodynamic investigation before and after APR for cancer. The urinary dysfunction rate was $7.7 \%$ for both genders [8] but no significant difference was found in any parameters of cystometric and urodynamic investigations in women after surgery ( $p>0.10$ for all comparisons) confirming that male patients are more at risk. Moreover, this study showed that patients with negligible symptoms of bladder outlet obstruction before surgery were likely to develop clinically relevant urinary symptoms after APR. Previous urological history was an independent risk factor in both our and Benoist's studies [3].

There are conflicting opinions regarding the superiority of open versus laparoscopy surgery for preservation of bladder function after rectal cancer surgery. Lim et al.'s recently published meta analysis did not show any difference between the two surgical approaches [13]. Similarly, we did not observe any influence of the approach. In the present work, there was however a significant positive influence of laparoscopy (??). However, laparotomy was chosen for more complicated patients. Also, the rate of laparoscopy was lower for APR while this group was most at risk of urinary dysfunction.

We observed that risk factors for urinary dysfunction were not significantly different between APR, MechCAA and ManCAA as did Benoist et al. [3] We also found that partial mesorectal excision was a protective factor of urinary function. We believe that SPC can be avoided after PME and CRA. In our department the rate of SPC after PME and CRA was only 33\%. Currently, the majority of male patients undergoing a PME are drained with TUC. 
Our score of three independent risk factors allowed to select low risk patients and to carry out a clamping test before POD5. Further studies are required to assess if a 3-day drainage would be feasible. If so, TUC may be preferable to SPC, which is recommended by the current guidelines [1]. Moreover, validation of this score on another population is mandatory.

Finally, the best type of drainage is still unknown. In their meta-analysis Jahn et al. were unable to draw practical conclusions from the comparison of SPC with TUC. SPC was not associated with a higher morbidity than TUC [10]. Ratnaval et al. compared SPC versus TUC in fifty consecutive male patients after rectal surgery in a prospective study [17]. Acute urinary retention rate was $20.8 \%$ (5 patients) for SPC and $23.1 \%$ (6 patients) for TUC. Recatheterization was necessary for 2 patients in SPC group and all of the TUC patients (7 AUR). Frequent voiding was recorded in 2 SPC versus 11 TUC $(\mathrm{p}<0.05)$. They concluded that SPC allowed a controlled return of normal voiding with fewer bladder and urethral symptoms. Studies on long-term urinary drainage do not add any useful information. Katsumi et al. studied the bladder management of male patients with spinal cord injury [11]. In this study of 179 patients with a long-term catheter there was no significant difference between the complication rates for the two catheter groups. However, the current trend in managing patients requiring an indwelling urinary catheter is to use a SPC in order to avoid the morbidity specifically associated with TUC.

Our study has several limits. Its retrospective design is associated with a risk of lost of data. However, due to the high volume of proctectomy in our department the inclusion period was short and the majority of data were collected exhaustively by our paramedical staff. Finally, the number of patients included should reduce this bias.

\section{Conclusion}

In this study the urinary dysfunction rate was $38 \%$ after surgery for rectal cancer. Drainage by SPC is not associated with a higher morbidity. SPC management is easier and more confortable for the patients. Three risk factors of urinary dysfunction (preoperative urological history, total mesorectal excision and diabetes mellitus) may serve to select those patients who are good candidates for early (POD2 or POD3) catheter removal.

\section{REFERENCES}

1. Alfonsi P, Slim K, Chauvin M et al. (2014) French guidelines for enhanced recovery after elective colorectal surgery. Journal of visceral surgery 151:65-79

2. Bennis M, Parc Y, Lefevre JH et al. (2012) Morbidity risk factors after low anterior resection with total mesorectal excision and coloanal anastomosis: a retrospective series of 483 patients. Ann Surg 255:504510 
3. Benoist S, Panis Y, Denet C et al. (1999) Optimal duration of urinary drainage after rectal resection: a randomized controlled trial. Surgery 125:135-141

4. Burgos FJ, Romero J, Fernandez E et al. (1988) Risk factors for developing voiding dysfunction after abdominoperineal resection for adenocarcinoma of the rectum. Dis Colon Rectum 31:682-685

5. Changchien CR, Yeh CY, Huang ST et al. (2007) Postoperative urinary retention after primary colorectal cancer resection via laparotomy: a prospective study of 2,355 consecutive patients. Dis Colon Rectum 50:1688-1696

6. Chaudhri S, Maruthachalam K, Kaiser A et al. (2006) Successful voiding after trial without catheter is not synonymous with recovery of bladder function after colorectal surgery. Dis Colon Rectum 49:10661070

7. Doeksen A, Gooszen JA, Van Duijvendijk P et al. (2011) Sexual and urinary functioning after rectal surgery: a prospective comparative study with a median follow-up of 8.5 years. Int J Colorectal Dis 26:1549-1557

8. Gerstenberg TC, Nielsen ML, Clausen S et al. (1980) Bladder function after abdominoperineal resection of the rectum for anorectal cancer. Urodynamic investigation before and after operative in a consecutive series. Ann Surg 191:81-86

9. Heald RJ (1995) Total mesorectal excision is optimal surgery for rectal cancer: a Scandinavian consensus. Br J Surg 82:1297-1299

10. Jahn P, Beutner K, Langer G (2012) Types of indwelling urinary catheters for long-term bladder drainage in adults. Cochrane Database Syst Rev 10:CD004997

11. Katsumi HK, Kalisvaart JF, Ronningen LD et al. (2010) Urethral versus suprapubic catheter: choosing the best bladder management for male spinal cord injury patients with indwelling catheters. Spinal cord 48:325-329

12. Lee SY, Kang SB, Kim DW et al. (2015) Risk factors and preventive measures for acute urinary retention after rectal cancer surgery. World J Surg 39:275-282

13. Lim RS, Yang TX, Chua TC (2014) Postoperative bladder and sexual function in patients undergoing surgery for rectal cancer: a systematic review and meta-analysis of laparoscopic versus open resection of rectal cancer. Tech Coloproctol 18:993-1002

14. Maas CP, Moriya Y, Steup WH et al. (1998) Radical and nerve-preserving surgery for rectal cancer in The Netherlands: a prospective study on morbidity and functional outcome. Br J Surg 85:92-97

15. O'kelly TJ, Mathew A, Ross S et al. (1995) Optimum method for urinary drainage in major abdominal surgery: a prospective randomized trial of suprapubic versus urethral catheterization. Br J Surg 82:1367-1368

16. Pocard M, Zinzindohoue F, Haab F et al. (2002) A prospective study of sexual and urinary function before and after total mesorectal excision with autonomic nerve preservation for rectal cancer. Surgery 131:368-372

17. Ratnaval CD, Renwick P, Farouk R et al. (1996) Suprapubic versus transurethral catheterisation of males undergoing pelvic colorectal surgery. Int J Colorectal Dis 11:177-179

18. Regenbogen SE, Read TE, Roberts PL et al. (2011) Urinary tract infection after colon and rectal resections: more common than predicted by risk-adjustment models. J Am Coll Surg 213:784-792

19. Sethia KK, Selkon JB, Berry AR et al. (1987) Prospective randomized controlled trial of urethral versus suprapubic catheterization. Br J Surg 74:624-625

20. Vandoni RE, Lironi A, Tschantz P (1994) Bacteriuria during urinary tract catheterization: suprapubic versus urethral route: a prospective randomized trial. Acta Chir Belg 94:12-16

21. Zaheer S, Pemberton JH, Farouk R et al. (1998) Surgical treatment of adenocarcinoma of the rectum. Ann Surg 227:800-811

22. Zmora O, Madbouly K, Tulchinsky $\mathrm{H}$ et al. (2010) Urinary bladder catheter drainage following pelvic surgery--is it necessary for that long? Dis Colon Rectum 53:321-326 


\begin{tabular}{|c|c|c|c|c|c|c|}
\hline & Overall & APR & MechCAA & ManCAA & CRA & $\mathrm{p}$ \\
\hline Median age & & $61.1 \pm 15.6$ & $64.4 \pm 10.5$ & $60.9 \pm 10.7$ & $65.2 \pm 11.9$ & NS \\
\hline Diabetes mellitus & $41(21 \%)$ & $10(20 \%)$ & $16(32 \%)$ & $7(14 \%)$ & $8(16 \%)$ & 0.19 \\
\hline Urological history & $25(12.5 \%)$ & $8(16 \%)$ & $6(12 \%)$ & $4(8 \%)$ & $7(14 \%)$ & 0.63 \\
\hline Previous abdominal surgery & $80(40 \%)$ & $26(52 \%)$ & $16(32 \%)$ & $15(30 \%)$ & $22(44 \%)$ & 0.07 \\
\hline BMI $\left(\mathrm{kg} / \mathrm{m}^{2}\right)$ & 24.9 & $25.5 \pm 3.8$ & $25.8 \pm 4.3$ & $22.5 \pm 4.6$ & $26 \pm 4.4$. & NS \\
\hline ASA score $1-2$ & $173(87 \%)$ & $41(82 \%)$ & $42(84 \%)$ & $47(94 \%)$ & $43(86 \%)$ & 0.31 \\
\hline Neoadjuvant Radiotherapy & $124(62 \%)$ & $42(84 \%)$ & $38(76 \%)$ & $35(70 \%)$ & $9(18 \%)$ & $<0.001$ \\
\hline \multicolumn{7}{|l|}{ Year of surgery } \\
\hline$<2008$ & $15(7 \%)$ & 13 & 1 & 1 & 0 & \\
\hline 2009 & $36(18 \%)$ & 9 & 14 & 5 & 8 & \\
\hline 2010 & $29(14.5 \%)$ & 5 & 9 & 10 & 5 & \\
\hline 2011 & $50(25 \%)$ & 10 & 10 & 14 & 16 & \\
\hline 2012 & $70(35 \%)$ & 13 & 16 & 20 & 21 & \\
\hline Laparoscopic approach & $84(42 \%)$ & $11(22 \%)$ & $18(36 \%)$ & $21(42 \%)$ & $34(68 \%)$ & $<0.001$ \\
\hline Conversion rate & $21(11 \%)$ & $2(4 \%)$ & $4(8 \%)$ & $4(8 \%)$ & $11(22 \%)$ & 0.66 \\
\hline $\begin{array}{l}\text { Associated } \\
\text { urologicalprocedures }\end{array}$ & $10(5 \%)$ & $3(6 \%)$ & $2(4 \%)$ & $3(6 \%)$ & $2(4 \%)$ & 0.94 \\
\hline \multicolumn{7}{|l|}{ Bladder drainage } \\
\hline SPC & $142(71 \%)$ & $42(84 \%)$ & $41(82 \%)$ & $45(90 \%)$ & $14(28 \%)$ & \multirow{2}{*}{$<0.001$} \\
\hline TUC & $58(29 \%)$ & $8(16 \%)$ & $9(18 \%)$ & $5(10 \%)$ & $36(72 \%)$ & \\
\hline Average operative time (min) & $279 \pm 66$ & $276 \pm 65.6$ & $277 \pm 74.4$ & $295.6 \pm 60.9^{*}$ & $266 \pm 59.6^{*}$ & 0.0257 \\
\hline \multicolumn{7}{|l|}{ Post-operative morbidity } \\
\hline Clavien 3-4 & $36(18 \%)$ & $6(12 \%)$ & $12(24 \%)$ & $12(24 \%)$ & $7(14 \%)$ & \multirow[t]{2}{*}{0.39} \\
\hline Clavien 5 & $3(1.5 \%)$ & 0 & 0 & 0 & $3(6 \%)$ & \\
\hline \multicolumn{7}{|l|}{ Pathological examination } \\
\hline $\mathrm{T} \leq 2$ & $78(39 \%)$ & $15(30 \%)$ & $20(40 \%)$ & $29(58 \%)$ & $14(28 \%)$ & \multirow{2}{*}{0.01} \\
\hline $\mathrm{T} \geq 3$ & $122(61 \%)$ & $35(70 \%)$ & $30(60 \%)$ & $21(42 \%)$ & $36(72 \%)$ & \\
\hline $\mathrm{N}+$ & $83(41.5 \%)$ & $24(48 \%)$ & $14(28 \%)$ & $22(44 \%)$ & $23(46 \%)$ & 0.16 \\
\hline $\mathrm{M}+$ & $16(8 \%)$ & $6(12 \%)$ & $6(12 \%)$ & $1(2 \%)$ & $3(6 \%)$ & 0.17 \\
\hline R0 & 182 (91\%) & $38(76 \%)$ & 47 (94\%) & 49 (98\%) & 48 (96\%) & 0.01 \\
\hline
\end{tabular}

Follow-up (months) 


\begin{tabular}{lllllll} 
Median & 504 & 459,5 & 593.5 & 513 & 389 & \\
& $8-2248$ & $13-2248$ & $45-1761$ & $8-1612$ & $10-1556$ & \\
Average & $601 \pm 470$ & 619.4 & 706.2 & 573 & 506.8 & \\
Recurrence & $39(20 \%)$ & $15(30 \%)$ & $7(14 \%)$ & $8(16 \%)$ & $9(18 \%)$ & 0.17 \\
\hline
\end{tabular}

Table 1. Characteristics of the cohort of 200 male patients operated for rectal cancer. 


\begin{tabular}{|c|c|c|c|c|c|}
\hline & Overall & APR & MechCAA & ManCAA & CRA \\
\hline Number of SPC & $136(71.6 \%)$ & $\begin{array}{c}39 \\
(83 \%)\end{array}$ & $\begin{array}{c}41 \\
(85 \%)\end{array}$ & $\begin{array}{c}42 \\
(92 \%)\end{array}$ & $\begin{array}{c}14 \\
(33 \%)\end{array}$ \\
\hline \multicolumn{6}{|c|}{ SPC removal } \\
\hline Before day 6 & $51 \%$ & $17(43.6 \%)$ & $18(44 \%)$ & $26(62 \%)$ & $8(57 \%)$ \\
\hline After day 7 & $49 \%$ & $22(56.4 \%)$ & $23(56 \%)$ & $16(38 \%)$ & $6(43 \%)$ \\
\hline Discharged with SPC & $6.5 \%$ & $3(7.7 \%)$ & $3(7.3 \%)$ & $2(4.8 \%)$ & $1(7 \%)$ \\
\hline \multicolumn{6}{|c|}{ Complications associated with SPC (15\%) } \\
\hline Accidental removal & $6(4.3 \%)$ & $2(5 \%)$ & $1(2.4 \%)$ & $3(7 \%)$ & 0 \\
\hline Haemorrhage & $4(2.9 \%)$ & $1(2.6 \%)$ & $1(2.4 \%)$ & $2(4.7 \%)$ & 0 \\
\hline Blockage & $4(2.9 \%)$ & $1(2.6 \%)$ & $2(4.9 \%)$ & 0 & $1(6.3 \%)$ \\
\hline Leakage & $6(4.3 \%)$ & $3(7.7 \%)$ & $2(4.9 \%)$ & $1(2.3 \%)$ & 0 \\
\hline \multicolumn{6}{|c|}{ Complications $(6 \%)$} \\
\hline Infection & $8(5.8 \%)$ & $2(5.1 \%)$ & $2(4.9 \%)$ & $4(9.3 \%)$ & 0 \\
\hline AUR & $0 \%$ & 0 & 0 & 0 & 0 \\
\hline Number of TUC & $54(28.4 \%)$ & $8(17 \%)$ & $7(15 \%)$ & $5(8 \%)$ & $34(67 \%)$ \\
\hline \multicolumn{6}{|c|}{ Complications $(9 \%)$} \\
\hline Infection & $3(6 \%)$ & 0 & $3(43 \%)$ & 0 & 0 \\
\hline AUR & $2(4 \%)$ & 0 & $1(14.3 \%)$ & 0 & $1(3 \%)$ \\
\hline Discharged with TUC & $2(4 \%)$ & 0 & $1(14.3 \%)$ & 0 & $1(3 \%)$ \\
\hline
\end{tabular}

APR: abdomino-perineal amputation, MechCAA: mechanic colo-anal anastomosis, ManCAA: manual coloanal anastomosis, CRA: colorectal anastomosis, SPC: suprapubic catherization, TUC: transurethral catheterization, AUR: acute urinary retention.

Table 2. Management and complications of urinary drainage 


\begin{tabular}{|c|c|c|c|c|c|c|c|c|c|c|c|c|}
\hline $\mathrm{N}^{\circ}$ & Age & $\begin{array}{l}\text { Diabe } \\
\text { tes }\end{array}$ & $\begin{array}{l}\text { Urolog } \\
\text { ical } \\
\text { history }\end{array}$ & $\begin{array}{l}\text { Radio } \\
\text { therapy }\end{array}$ & Surger & & $\begin{array}{c}\text { Morbidit } \\
\text { y } \\
\text { Clavien } \\
\text { Score }\end{array}$ & $\mathrm{pT}$ & $\begin{array}{c}\text { Type of } \\
\text { bladder } \\
\text { drainage }\end{array}$ & $\begin{array}{c}\text { Total } \\
\text { time of } \\
\text { drainage }\end{array}$ & AUR & $\begin{array}{c}\text { Urinar } \\
\text { y } \\
\text { infecti } \\
\text { on }\end{array}$ \\
\hline 1 & 71 & YES & & YES & APR & $\mathrm{LT}$ & 2 & 4 & SPC & 44 & & \\
\hline 2 & 71 & & YES & & APR & LT & 0 & 2 & SPC & 57 & & \\
\hline 3 & 77 & & YES & YES & APR & LT & 0 & 0 & SPC & 41 & & YES \\
\hline 4 & 48 & & & YES & $\begin{array}{c}\text { ManCA } \\
\text { A }\end{array}$ & LC & 1 & 2 & SPC & 60 & & YES \\
\hline 5 & 56 & & & YES & $\begin{array}{c}\text { ManCA } \\
\text { A }\end{array}$ & LT & 1 & 2 & SPC & 45 & & YES \\
\hline 6 & 58 & & & YES & $\begin{array}{c}\text { MechC } \\
\text { AA }\end{array}$ & LC & 3 & 2 & SPC & 50 & & YES \\
\hline 7 & 77 & YES & YES & YES & $\begin{array}{c}\text { MechC } \\
\text { AA }\end{array}$ & LC & 3 & 2 & SPC & 64 & & \\
\hline 8 & 68 & & & & $\begin{array}{c}\text { MechC } \\
\text { AA }\end{array}$ & LC & 1 & 1 & SPC & 40 & & \\
\hline 19 & 69 & & YES & YES & $\begin{array}{c}\text { MechC } \\
\text { AA }\end{array}$ & LT & 3 & 3 & TUC & 58 & YES & YES \\
\hline 10 & 41 & YES & & YES & CRA & $\mathrm{LT}$ & 3 & 4 & SPC & 259 & & \\
\hline 11 & 62 & & & & CRA & LC & 3 & 3 & TUC & 22 & YES & \\
\hline
\end{tabular}

APR: abdomino-perineal amputation, MechCAA: mechanic colo-anal anastomosis, ManCAA: manual coloanal anastomosis, CRA: colorectal anastomosis, SPC: suprapubic catherization, TUC: transurethral catheterization, AUR: acute urinary retention, LC: laparoscopy, LT: laparotomy.

Table 3. Characteristics of patients with failed catheter removal 


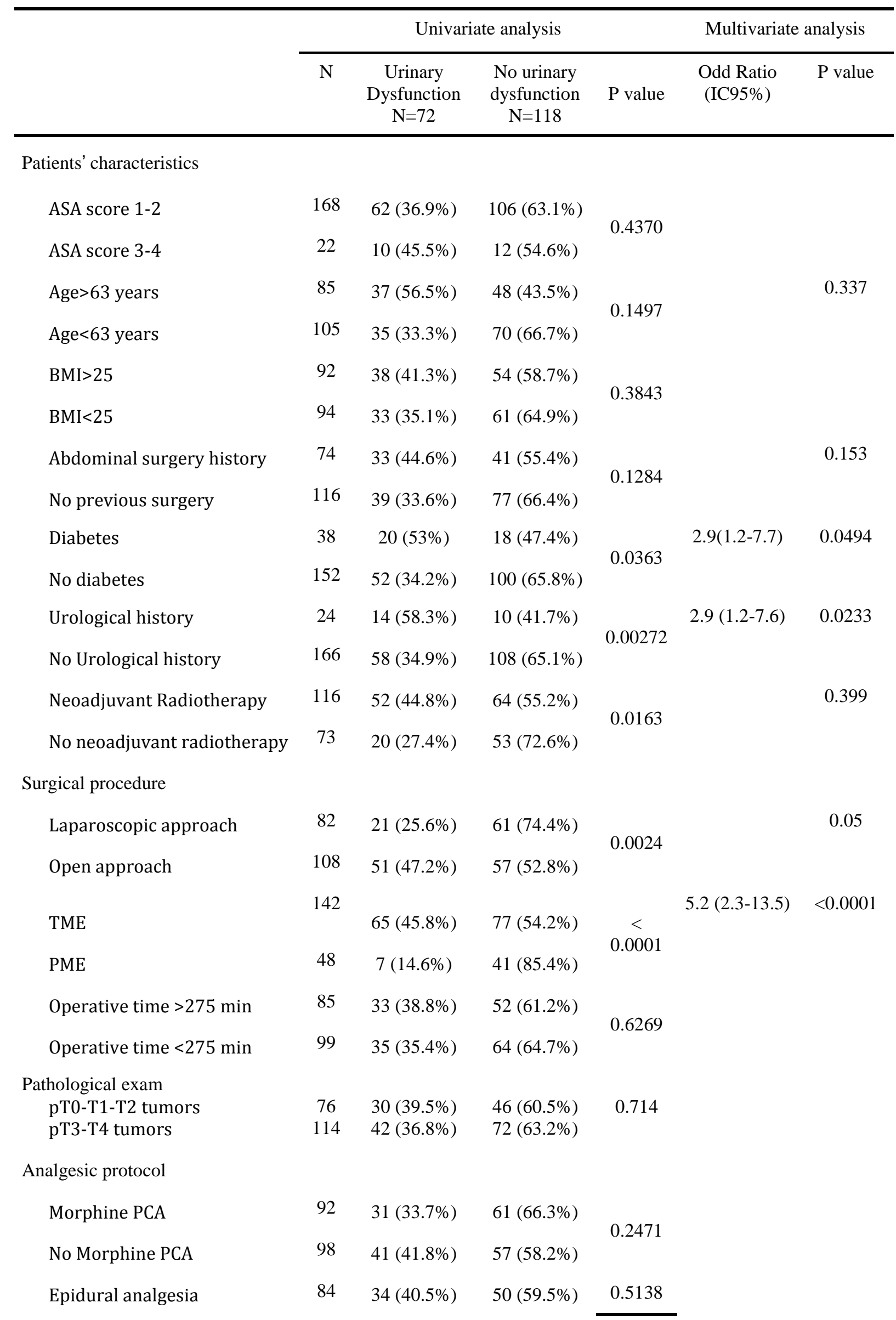


Table 4. Univariate and multivariate analysis of risk factors associated with post-operative urinary dysfunction. 
